F. VROEGINDEWEIJ
E.A. SPEETS
J.A.J. STEEN $^{2}$
J. BRUGGER
D.H.A. BLANK

F. VROEGINDEWEIJ ${ }^{1, \infty}$

E.A. SPEETS

J. BRUGGER ${ }^{2}$

D.H.A. BLANK ${ }^{1}$

\section{Exploring microstencils for sub-micron patterning using pulsed laser deposition}

\author{
${ }^{1}$ University of Twente and MESA ${ }^{+}$Institute for Nanotechnology, Faculty of Science \& Technology, \\ P.O. Box 217, 7500 AE Enschede, The Netherlands \\ ${ }^{2}$ Microsystems Laboratory, Ecole Polytechnique Fédérale de Lausanne (EPFL), 1015 Lausanne, Switzerland
}

\begin{abstract}
Received: 6 October 2003/Accepted: 4 March 2004 Published online: 26 July 2004 • (C) Springer-Verlag 2004

ABSTRACT The possibilities of sub-micron patterning by means of microstencils using pulsed laser deposition were investigated. Stencils with circular and elliptical patterns were used, with pore sizes ranging from $1 \mu \mathrm{m}$ down to $500 \mathrm{~nm}$. Strontium titanate $\left(\mathrm{SrTiO}_{3}\right)$, silicon $(\mathrm{Si})$ and self-assembled monolayers on gold were used as substrate materials, whereas nickel $(\mathrm{Ni})$, nickel oxide $(\mathrm{NiO})$ and gold $(\mathrm{Au})$ have been deposited. The results show that the chosen deposition setup makes an easy and fast way for high-quality pattern creation.
\end{abstract}

PACS 81.15.Fg; 81.16.Rf; 68.37.Ps

\section{1}

\section{Introduction}

One of the main aims of today's research in the fields of, for example, electronic devices and materials science, is the ability of downsizing. Besides developing lowcost and high-throughput processes, decreasing to micro- or nano-sized dimensions is of great importance. Reduced chip dimensions can increase the integration, which makes cheaper production possible. However, conventional patterning processes based on photoresist methods are difficult to be applied to fragile structures, such as self-assembled monolayers (SAMs). Direct resistless patterning would provide a major improvement, such as the recently demonstrated thermal evaporation of nanostructures through miniature shadow masks (microstencils) [1].

Patterning by microstencils can be used in different areas, for instance for data storage using magnetic dots, counterelectrodes on soft condensed matter, pattern recognition in chip design similar to Braille, etc. Our goals were threefold. Firstly, to investigate the possibilities of applying patterned areas in new thin-layer gas-sensor designs. Secondly, applying patterned areas on SAMs for their electrical investigation and, thirdly, the realization and investigation of nanoscale electrical devices.

We used pulsed laser deposition (PLD) to produce the islands. PLD is a well-known technique for the growth of highquality thin layers. Besides being easy to use, this thin-layerdeposition method is a versatile technique, which enables the

Fax: +31-53-489-4683, E-mail: f.vroegindeweij@utwente.nl use of a wide range of different materials and substrates. Easy adjustment of the deposition parameters permits fine tuning of the deposited layers. Furthermore, PLD enables us to deposit materials in a wide pressure regime. The latter will be an important parameter to obtain sharp imprints.

\section{$2 \quad$ Experimental}

Pulsed laser deposition has some interesting advantages over other evaporation techniques, especially in the application of microstencils. Besides the ease of use of the system and the wide range of possible materials to ablate, the broad usable pressure regime and highly energetic particles are the key features that enable a sharp imprint on the substrate. E-beam evaporation can also be used, although the species have lower energies compared to PLD; sputter deposition on the other hand fails since the stencil acts as a plate capacitor.

The pulsed laser deposition system is equipped with a $\mathrm{KrF}$ laser $(248 \mathrm{~nm})$ and has a typical base pressure of $10^{-7} \mathrm{mbar}$. The substrate is placed opposite to the target, while the target is rotated during deposition. The purity of the target materials is better than $99.99 \%$.

Two types of experiments have been carried out. First, to investigate the ability of depositions through microstencils, experiments with the deposition of nickel (Ni), nickel oxide $(\mathrm{NiO})$ and gold $(\mathrm{Au})$ islands on single-terminated $\mathrm{SrTiO}_{3}$ substrates were performed. The substrates are pre-cleaned ultrasonically with acetone and ethanol to remove possible contaminations. Next, they are chemically etched and annealed to obtain a $\mathrm{TiO}_{2}$ termination [2]. Secondly, $\mathrm{Au}$ islands were deposited on octadecanethiolate $\left(\mathrm{C}_{18} \mathrm{SH}\right) \mathrm{SAMs}$ on gold. The $\mathrm{Au}$ islands can be used as electrodes, which are separated from the gold substrate by an insulating layer. This insulating layer has a typical thickness of $2 \mathrm{~nm}$, depending on the SAM used [3].

During these experiments, three types of stencils have been used $[1,4]$ : stencils with circular holes with a diameter of $1.2 \mu \mathrm{m}$ and $500 \mathrm{~nm}$, respectively, and elliptical holes $(1 \times 3 \mu \mathrm{m})$. The first stencil has four patterned areas of $0.1 \times$ $0.9 \mathrm{~mm}^{2}, 0.9 \mu \mathrm{m}$ pore-to-pore sizes and a thickness of $1.0 \mu \mathrm{m}$. The second stencil has pore-to-pore sizes of $0.7 \mu \mathrm{m}$ and $1.7 \mu \mathrm{m}$, and a patterned area of $1.0 \times 3.0 \mathrm{~mm}^{2}$, which is extremely large compared to the other stencils used. The third 


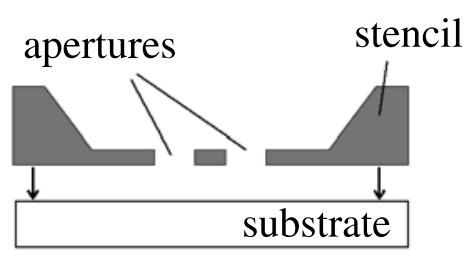

evaporation

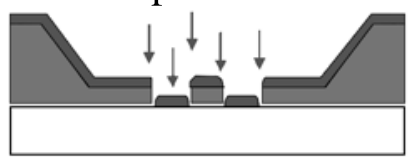

deposited pattern
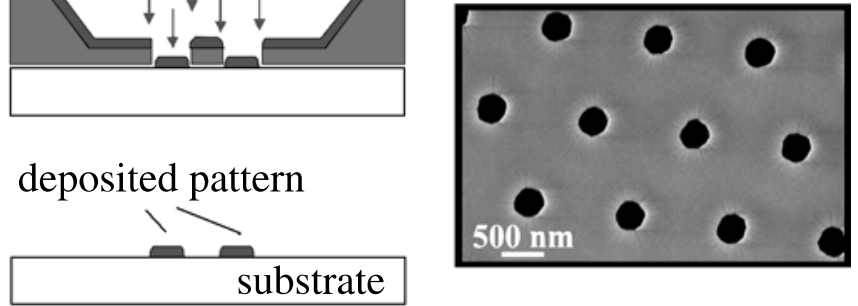

FIGURE 1 The principle of submicron stencil patterning. Material is evaporated through the shadow mask using pulsed laser deposition. The scanning electron image on the right shows a typical mask with 300-nm apertures

\begin{tabular}{|c|c|c|c|c|}
\hline Parameter & $\mathrm{Ni}$ & $\mathrm{NiO}$ & $\mathrm{Au} *$ & $\mathrm{Au}^{* *}$ \\
\hline $\begin{array}{l}\text { Gas pressure } \\
{[\mathrm{mbar}]}\end{array}$ & $4.0 \times 10^{-4}$ & $3.5 \times 10^{-2}$ & $6.0 \times 10^{-4}$ & $1.0 \times 10^{-7}$ \\
\hline $\begin{array}{l}\text { Gas flow } \\
{\left[\mathrm{ml} \mathrm{min}^{-1}\right]}\end{array}$ & $2.5 \mathrm{Ar}$ & $2.1 \mathrm{O}_{2}$ & 4.0 Ar & $2.0 \mathrm{Ar}$ \\
\hline $\begin{array}{l}\text { Laser fluence } \\
{\left[\mathrm{J} \mathrm{cm}^{-2}\right]}\end{array}$ & 5.0 & 4.5 & 4.0 & 5.0 \\
\hline $\begin{array}{l}\text { Laser frequency } \\
{[\mathrm{Hz}]}\end{array}$ & 10 & 5 & 4 & 8 \\
\hline No. of pulses & $\begin{array}{c}900 * \\
3000 * *\end{array}$ & 1500 & 600 & 1440 \\
\hline $\begin{array}{l}\text { Spot size } \\
{\left[\mathrm{mm}^{2}\right]}\end{array}$ & 2.4 & 2.4 & 2.4 & 1.8 \\
\hline $\begin{array}{l}\text { Target-substrate } \\
\text { distance } \\
{[\mathrm{mm}]}\end{array}$ & 42.0 & 42.0 & 48.0 & 42.0 \\
\hline
\end{tabular}

TABLE 1 Deposition parameters of the materials deposited through the microstencils during pulsed laser deposition

stencil has a thickness of $500 \mathrm{~nm}$, a patterned area of $0.9 \mathrm{~mm}^{2}$ and pore-to-pore sizes of $1.6 \mu \mathrm{m}$. The stencil thickness is $1.2 \mu \mathrm{m}$. The microstencil-production process is described in detail by van Rijn et al. [5].

The principle of submicron stencil patterning is depicted in Fig. 1, as is a scanning electron image of a stencil with 300-nm apertures. The stencil is glued on an aluminum holder. The stencil including holder is gently pressed onto the substrate by screws. The stencil-to-substrate distance turns out to be one of the critical parameters. When the stencil is not pressed firmly enough onto the substrate, undergrowth may occur. However, if the stencil is pressed too hard, the stencil may bend, which causes undergrowth or even breaking of the stencil. Also, damaging of the substrate may occur when the stencil is pressed too hard, especially in the case of SAMs.

In these experiments, only stencils with regularly spaced apertures have been investigated. However, it is possible to create a unique design of distributed apertures by changing the stencil design, by blocking certain parts of the patterned area during deposition or by partly etching the deposited islands.

The deposition parameters used are depicted in Table 1.
After deposition, the deposited islands were investigated by contact-mode (CM), lateral-force-mode (LFM) and tapping-mode (TM) atomic force microscopy (AFM) analysis.

\section{Results and discussion}

Figure 2 shows a typical CM-AFM image $(5 \times$ $5 \mu \mathrm{m}^{2}$ ) recorded on 5.2-nm-high as-deposited Ni islands on a $\mathrm{SrTiO}_{3}$ substrate, deposited through the stencil with $1.2-\mu \mathrm{m}$ circular apertures. The deposition parameters used are given in Table $1\left(\mathrm{Ni}^{*}\right)$.

The islands are well defined and completely isolated. Due to the small dimensions of the islands, it is impossible to check the morphology, crystallinity or composition of the deposited material by, for example, reflective high energy electron diffraction (RHEED), X-ray diffraction (XRD) or X-ray photoelectron spectroscopy (XPS). The fact that the typical substrate terraces $\left(\mathrm{TiO}_{2}\right.$-terminated $\left.\mathrm{SrTiO}_{3}\right)$ are still visible on top of the islands indicates high-quality growth. AFM analysis shows that the islands measure $1.3 \mu \mathrm{m}$ on the base, which indicates a minor broadening effect of less than $10 \%$, which is better then expected. It is likely that material tends to diffuse under the stencil due to the mobility of the particles on arrival at the substrate. Although all the depositions are done at room temperature, the ablated species have a high activation energy [6]. The gas pressure during deposition turns out to be an important parameter. This is clearly shown in Fig. 3, which shows a $2 \times 2 \mu \mathrm{m}^{2} \mathrm{CM}$-AFM height (left) image and a LFM-AFM (right) image of consecutive depositions of $\mathrm{NiO}$
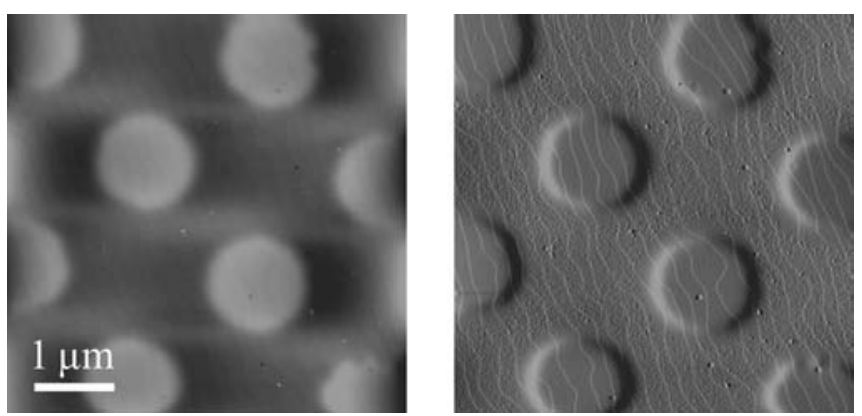

FIGURE $25 \times 5 \mu \mathrm{m}^{2}$ CM-AFM image of 5.2-nm-high $\mathrm{Ni}$ islands on a $\mathrm{SrTiO}_{3}$ substrate. Height (left) and deflection (right) images. The deposition parameters used are a $5.0 \mathrm{~J} \mathrm{~cm}^{-2}$ fluence, $4.0 \times 10^{-4} \mathrm{mbar}$ Ar pressure, $2.5 \mathrm{ml} \mathrm{min}^{-1}$ Ar flow and a $42.0 \mathrm{~mm}$ target-substrate distance
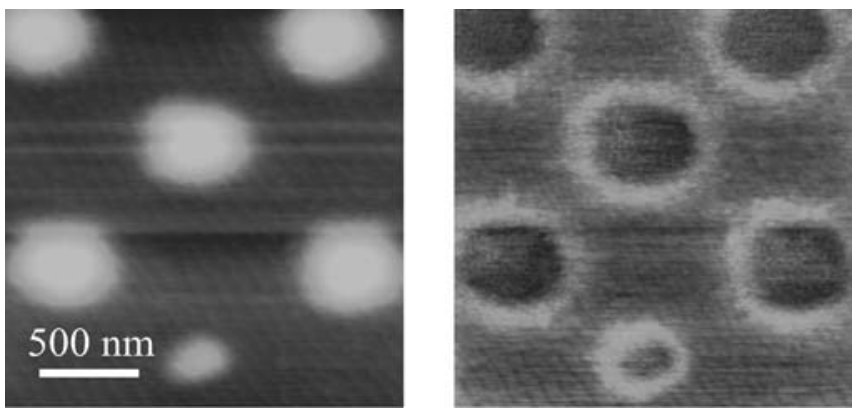

FIGURE $32 \times 2 \mu \mathrm{m}^{2}$ CM-AFM height (left) and LFM-AFM (right) images of consecutive depositions of $\mathrm{NiO}$ and $\mathrm{Au}$ through a stencil, under different gas pressures. The deposition parameters used for $\mathrm{NiO}(\mathrm{Au})$ are a $4.5(4.0) \mathrm{J} \mathrm{cm}^{-2}$ fluence, $3.5 \times 10^{-2} \mathrm{O}_{2}\left(6.0 \times 10^{-4}\right.$ Ar) pressure, 2.1 (4) $\mathrm{ml} \mathrm{min}^{-1} \mathrm{O}_{2}$ (Ar) flow and a 42.0 (48.0) $\mathrm{mm}$ target-substrate distance 

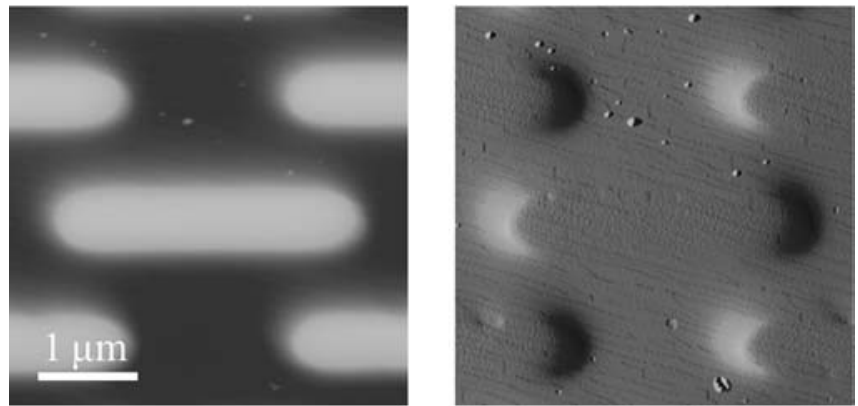

FIGURE $44 \times 4 \mathrm{~mm}^{2}$ CM-AFM image of 50.0-nm-high $\mathrm{Ni}$ islands on a $\mathrm{SrTiO}_{3}$ substrate. Height (left) and deflection (right) images. The deposition parameters used are a $5.0 \mathrm{~J} \mathrm{~cm}^{-2}$ fluence, $4.0 \times 10^{-4} \mathrm{mbar}$ Ar pressure, $2.5 \mathrm{ml} \mathrm{min}{ }^{-1}$ Ar flow and a $42.0 \mathrm{~mm}$ target-substrate distance

and Au through the stencil with 500-nm circular apertures, under different gas pressures [7]. The deposition parameters are given in Table $1\left(\mathrm{Au}^{*}\right)$. Since the $\mathrm{NiO}$ has been deposited with a lower gas pressure, a larger broadening effect is visible. Also, the mobility can be optimized by varying the fluence of the laser beam, or by pressing the stencil harder onto the substrate, though damaging of the substrate or bending of the patterned area must be avoided.

Figure 4 shows the $4 \times 4 \mu \mathrm{m}^{2}$ CM-AFM height (left) image and the deflection (right) image of 50-nm-high asdeposited $\mathrm{Ni}$ islands on $\mathrm{SrTiO}_{3}$, deposited through the stencil with elliptical apertures $(1 \times 3 \mu \mathrm{m})$. The deposition parameters are given in Table $1\left(\mathrm{Ni}^{* *}\right)$.

Again, the islands are well defined and clearly separated from each other, as the AFM picture demonstrates. Though not clearly visible, AFM analysis shows that the terrace steps are still present on top of the 50-nm-high Ni islands. It has been demonstrated that this is possible even up to 70-nm-high islands, which again marks the possibilities of the PLD system to grow ultra-smooth and homogeneous thin films.

The stencils can be used multiple times, depending on the amount of material deposited. During deposition, material is also deposited on top of the stencil, as well as on the aperture walls, resulting in a gradual filling. Moreover, at some point, the deposited layer on top of the stencil causes a visible bending of it due to tensile stress. This effect only occurred using the stencil with the $1 \times 3-\mu$ m elliptical apertures, which is due to the extremely small thickness to area ratio. Since the area bends away from the substrate, the stencil cannot be properly pressed onto the substrate, which hampers the deposition of well-defined islands. Bending of the stencil and undergrowth both result in interconnected, vague islands, which cannot be used for the intended applications. Choosing smaller membranes can reduce the effect. Stencils used for gold depositions could be cleaned with an aqueous gold-etch solution [8].

Figure 5 shows the $20 \times 20 \mu \mathrm{m}$ TM-AFM height image of 17-nm-high as-deposited $\mathrm{Au}$ islands on a $\mathrm{C}_{18} \mathrm{SH} \mathrm{SAM}$, deposited through the stencil with $500-\mathrm{nm}$ circular apertures. The deposition parameters are given in Table $1\left(\mathrm{Au}^{* *}\right)$.

The islands are well defined and clearly separated from each other, as investigation of the AFM data shows. The islands measure about $600 \mathrm{~nm}$ in diameter, which indicates a high $(20 \%)$ degree of undergrowth. This can be caused by a bad stencil-substrate contact, or by the high mobility of gold on the very apolar SAM surface.

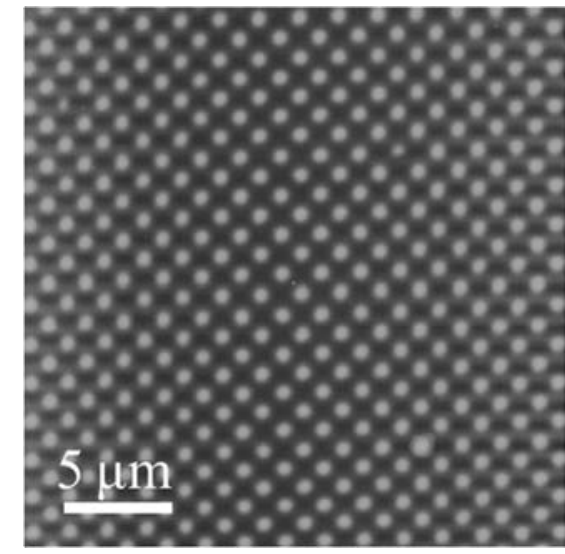

FIGURE $520 \times 20 \mu \mathrm{m}^{2}$ TM-AFM height image of about 17-nm-high asdeposited $\mathrm{Au}$ islands on a $\mathrm{C}_{18} \mathrm{SH}$ SAM. The deposition parameters used are

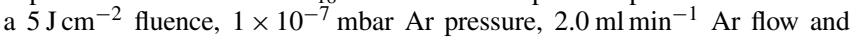
a $42.0 \mathrm{~mm}$ target-substrate distance

\section{$4 \quad$ Conclusions}

Microstencils have been successfully used to deposit grids of micro-islands onto various substrates by PLD. Pore sizes ranged from $3 \mu \mathrm{m}$ down to $500 \mathrm{~nm}$. AFM analyses show islands which are perfectly separated and well defined over a large area, with a very smooth morphology. Electrochemical copper deposition experiments from an aqueous $\mathrm{CuSO}_{4} / \mathrm{H}_{2} \mathrm{SO}_{4}$ solution, using the sample with gold islands as working electrode, showed that the use of microstencils during PLD is a suitable technique for the creation of electrically isolated gold islands on SAMs [9]. The gap between the stencil and the substrate, the fluence of the laser and the gas pressure during deposition are critical parameters of deposition using shadow masks. The results were obtained using $\mathrm{Ni}, \mathrm{NiO}$ and $\mathrm{Au}$ as through-deposited materials. Bending of the patterned area must be avoided by carefully choosing the dimensions of this area. New experiments involve the use of stencils with circular holes down to $100 \mathrm{~nm}$ in diameter and the use of cantilever-shaped stencils.

ACKNOWLEDGEMENTS We would like to acknowledge Bart Jan Ravoo and David N. Reinhoudt for their efforts and discussions on $\mathrm{Au}$ islands deposited on SAMs.

\section{REFERENCES}

1 J. Brugger, J.W. Berenschot, S. Kuiper, W. Nijdam, B. Otter, M. Elwenspoek: Microelectron. Eng. 53, 403 (2000)

2 G. Koster, B.L. Kropman, A.J.H.M. Rijnders, D.H.A. Blank, H. Rogalla: Appl. Phys. Lett. 73, 2920 (1998)

3 J. Lee, G. Lientschnig, F. Wiertz, M. Struijk, R.A.J. Janssen, R. Egberink, D.N. Reinhoudt, P. Hadley, C. Dekker: Nano Lett. 3, 113 (2003)

4 C.J.M. van Rijn, W. Nijdam: Aquamarijn Micro Filtration bv [http://www.microsieve.com]

5 C.J.M. van Rijn, G.J. Veldhuis, S. Kuiper: Nanotechnology 9, 343 (1998)

6 A.J.H.M. Rijnders: Thesis, University of Twente (2001) [ISBN 90-3651657-9]

7 J.A.J. Steen: 'Sub-micron Patterning with Shadowmasks Using Pulsed Laser Deposition'. Master's Thesis, University of Twente (2002)

8 Y.N. Xia, G.M. Whitesides: Angew. Chem. Int. Ed. 37, 551 (1998)

9 E.A. Speets, B.J. Ravoo, F.J.G. Roesthuis, F. Vroegindeweij, D.H.A. Blank, D.N. Reinhoudt: Nano Lett. 4(5), 841 (2004) 